\title{
OS ETHÉ DO PARECERISTA DE PARECERES PUBLICADOS NA REVISTA ENCONTROS BIBLI
}

\section{ETHÉ OF REVIEWERS OF PUBLISHED REVIEWS IN THE JOURNAL ENCONTROS BIBLI}

\author{
Márcia Sipavicius Seide \\ Universidade Estadual do Oeste do Paraná ${ }^{1}$
}

\begin{abstract}
RESUMO
Observa-se, a partir de 2003, uma proliferação de revistas científicas on line no Brasil fomentada pelo uso da plataforma Open Journal System cuja versão em língua portuguesa foi fomentada pelo IBICT como parte do movimento da Ciência Aberta. Como consequência da implementação desta agenda, existem revistas que publicam pareceres o que oportuniza que este gênero seja melhor descrito e conhecido. Neste contexto, este artigo analisa o ethos (a imagem de si) do autor de parecer publicado mediante identificação dos recursos linguísticos e das estratégias retóricas empregadas para tanto. Na primeira seção, apresentam-se as teorias nas quais a pesquisa se embasa, a Linguística Funcional e a Retórica, e alguns estudos anteriores sobre o assunto; na segunda seção, descreve-se a metodologia empregada para a constituição do corpus formado por 10 pareceres publicados na revista Encontros Bibli em 2019 e em 2020; na terceira seção, há a identificação e descrição das estratégias empregadas no corpus para constituição do ethé do pareceristas e, ao final, são feitas considerações finais sobre as contribuições e limitações da pesquisa. Os resultados da análise da amostra de pareceres evidenciam que o contexto da avaliação de artigos científico, os ideais da Ciência Aberta e a imagem de si buscada pelos pareceristas dos pareceres do corpus analisado reconfiguraram as qualidades apontadas primeiramente por Aristóteles e reconfiguradas hoje em dia pela imagem de si criada pelos pareceristas: a do parecerista objetivo e neutro, a do parecerista respeitoso, polido e educado e a do parecerista democrático e aberto.
\end{abstract}

PALAVRAS-CHAVE: Linguística Funcionalista; Retórica; pareceres publicados; ethos.

\begin{abstract}
Since 2003, there is a proliferation of scientific journals on line in Brazil fostered by the use of the Open Journal System whose Portuguese-language version was promoted by IBICT as a first stage of the Open Science movement. Later steps of this movement include opening the process of evaluating articles, sharing primary data and pre-published articles into preprint repositories. As a consequence of the implementation of this agenda there are Brazilian journals that publish reviews of article. The publication of those texts enables this genre to be better described and known. In this context, this article analyses the ethos of the author of a review published by identifying the linguistic resources and rhetorical strategies employed for this. In the first section, theories on which the research is based, Functional Linguistics and Rhetoric, and some previous studies on the subject are presented; in the second section, the methodology used for the constitution of the corpus formed by 10 published in Encontros Bibli journal in 2019 and 2020 is described; in the third section, there is identification and description of the strategies employed in the corpus to establish the ethe of the reviewers and, at the end, final remarks are made about the contributions and limitations of the research. The qualities of the classic ethos, according to Aristotle, focus on equity, a sense of justice, impartiality, exemption and neutrality are still present in the ethé analysed. The results of the analysis of the sample of reviewer's texts show that the context of the evaluation of scientific articles, the ideals of Open Science and the image of oneself sought by the reviewers of
\end{abstract}

\footnotetext{
${ }^{1}$ Doutora em Filologia e Língua Portuguesa pela FFLCH-USP (2006), marciaseda4@hotmail.com
} 
the opinions of the analysed corpus reconfigured the qualities pointed out by the philosopher in three ethé the objective and neutral reviewer, the respectful, polished and educated reviewer and the democratic and open mind reviewer.

KEYWORDS: Functionalist Linguistics; Rhetoric; published review texts; Ethos.

\section{INTRODUÇÃO}

Há, cada vez mais, no contexto das revistas científicas no Brasil, incentivo para que as publicações brasileiras se comprometam com os ideais da Ciência Aberta. O primeiro passo nesta direção ocorreu em 2003 quando foi disponibilizada, gratuitamente, uma plataforma para criação e manutenção de revista on line, o Sistema Eletrônico para Editoração de Revista (SEER) e, por iniciativa do Ibict, a tradução do software Open Journal Systems (OJS).

O acesso aberto tanto para publicação de artigos quanto para o acesso a eles, leitura e uso de revistas científicas foi incentivado pela Declaração de Budapeste firmada em 2002 e reconfirmada em 2012 (ALBAGLI; CLINIO; RAYCHTOCK, 2014, p.438). Desde então, há um crescente número de revistas on line no Brasil, com inclusão da Revista do GELNE que também faz uso desta modalidade de publicação. A implementação das demais etapas do processo apregoado pelo movimento da Ciência Aberta, contudo, tem encontrado resistência e suscitado controvérsias, especialmente na área de Letras e Linguística e no que se refere à abertura do sistema de avaliação de artigos

Há várias estratégias de aproximação aos ideais da Ciência Aberta no que tange a avaliação de artigos. Beziak et al as descrevem da seguinte maneira: uma revista pode possibilitar e incentivar o processo aberto de revisão pelos pares no qual tanto autor quanto pareceristas sabem a identificação um do outro. Outra alternativa, apontam os autores, é motivar a publicação dos pareceres, neste caso, o parecer é publicado junto com o artigo avaliado. Estas medidas, esclarecem, podem ser complementadas por outras que possibilitem a participação aberta pela qual os leitores e a comunidade em geral podem opinar e contribuir com o processo de revisão do artigo. Continuando suas explicações, os autores sugerem que a própria interação entre o autor do artigo e o parecerista pode se tornar aberta, neste caso, ambos podem dialogar direta e livremente sobre o artigo submetido à revista; outa medida nesta direção é o editor da revista motivar os revisores a conversarem entre si sobre a avaliação do artigo. Outra medida possível, ainda de acordo com os autores, é a publicação antecipada de artigos previamente à revisão pelos pares o que se consegue quando o autor deposita o artigo em repositórios de pré print e há revistas que aceitam a submissão de textos previamente publicado nesses repositórios, ou quando a própria revista publica os artigos a ela submetidos antes da revisão pelos pares. (BEZIAK et al., 2018).

Como se percebe pela descrição dos autores, a possibilidade de se publicar pareceres em decorrência da adesão dos editores de revistas acadêmicas aos ideais da Ciência Aberta traz alterações significativas para este gênero discursivo, decorrentes da mudança dos interlocutores e dos meios de circulação do parecer ${ }^{2}$. Considerando esta possibilidade existem, ao menos, duas configurações para o gênero: de um lado, o parecer tradicional anônimo e sigiloso escrito para ser lido pelo editor da revista e pelo autor do artigo e o parecer aberto que pode ou não ser anônimo, é escrito para tornar-se público e poderá ser lido por todos os leitores da revista.

Tendo isto em vista, o objetivo deste artigo é analisar o ethos (a imagem de si) que o autor de parecer publicado cria em seus pareceres mediante identificação dos recursos linguísticos e das estratégias retóricas empregadas para tanto. Uma breve revisão de literatura de artigos publicados em língua portuguesa sobre o processo de avaliação de artigos científicos indica que ainda não foi publicada neste idioma uma pesquisa sobre como pareceristas de pareceres publicados criam para

\footnotetext{
${ }^{2}$ Não faz parte do escopo deste artigo uma avaliação positiva ou negativa do movimento das Ciência Abertas tendo em vista que a pesquisa realizada se centra em observar algumas características deste novo gênero discursivo que surgiu em decorrência desse movimento: o parecer publicado.
} 
si determinada imagem. Vasconcellos (2017) trata do processo de revisão cega por pares em revistas científicas com o objetivo de apontar parâmetros de qualidades de pareceres consistentes. Também preocupado com a qualidade em si do parecer, há a classificação de critérios para aferição da qualidade do parecer pelo editor de revista proposta por Trzesniak, Tatiana Plata-Caviedes e Oscar Alejandro Córdoba-Salgado (2012). Job, Mattos e Trindade (2009), por sua vez, investigaram os motivos pelos quais os pareceristas rejeitam determinados artigos. Há também o estudo de Oliveira, Porto e Queiróz (2010) sobre os aspectos estruturais e retóricos da linguagem científica valorizados por estudantes. Se, bem pela utilização da Retórica, o artigo deles se assemelha a este, dele se diferencia em virtude de o objeto de estudo dos pesquisadores ser a revisão que estudantes de Química fazem de textos escritos por outros estudantes em grupos de revisão pelos pares (Peer Group Review). Bem semelhante às análises apresentadas aqui são as realizadas por da Cruz (2012). Em suas teses de doutorado a pesquisa analisou 67 pareceres (de aprovação, de reprovação e aprovação condicionada) enviados à uma mesma revista da área da Linguística pela perspectiva sistêmico-funcional, a mesma utilizada neste artigo. Diferentemente de sua pesquisa, contudo, a pesquisa apresentada neste artigo se baseia não em pareceres anônimos, mas sim em pareceres autorais e publicados nos quais há aprovação ou aprovação condicionada dos artigos, uma possiblidade recente no meio acadêmico brasileiro em geral e especialmente na área de Letras na qual não se encontrou nenhuma revista que publica pareceres de artigo. Outra diferença está na fundamentação teórica utilizada que integra os estudos retóricos aos funcionalistas.

\section{0 parecer de artigo científico}

Do ponto de vista da Linguística Funcional, a linguagem serve para seus usuários satisfazerem suas necessidades e se molda à cultura e à sociedade nas quais é utilizada. No que respeita os recursos linguísticos de que a linguagem se vale, pode-se mapear esta função pelo uso da modalidade. A expressão da avaliação em textos, contudo, requer um estudo mais amplo que contemple a sociedade e a cultura nas quais a avaliação é feita e que possa elucidar como é feita a conexão entre a atividade social de avaliar algo no mundo e a atividade textual de expressão dessa avaliação (BOLÍVAR, 2002, p.133).Existe um acordo tácito entre os participantes da interação social estabelecida pelo texto sobre a função avaliativa primordial de alguns gêneros discursivos, feita a ressalva de que não há equivalência entre os participantes do mundo real e os participantes do mundo discursivamente criado no nível do texto (BOLÍVAR, 2002, p.134). Tendo em vista que, no texto, o escritor representa os demais participantes do evento comunicativo que se instaura, a Linguística Funcional parte do pressuposto de que os escritores decidem o que e como escrevem em função daquilo que sabem sobre quem são seus leitores, o que eles sabem e que sistemas de valores eles têm, o que inclui aquilo que eles apoiam e o que eles rejeitam de modo que a interação autor-leitor guia as escolhas do escritor deste a primeira linha do seu texto (BOLÍVAR, 2002, p.135136).

Considerando as funções a que se prestam os usos da linguagem, o parecer de artigo científico tem, como função principal, a avaliação e o avaliador representa, no seu parecer, a si mesmo e aos demais participantes da comunicação: editor e autor no caso dos pareceres sigilosos e editor, autor e leitores da revista, no caso dos pareceres publicados. ${ }^{3}$ Em sua pesquisa sobre a função avaliativa em textos escritos, Bolívar defende que se levem em consideração a conexão do texto com a sociedade e as representações que o autor faz dos participantes reais do evento, com inclusão de seus valores e de suas ideologias. Do ponto de vista adotado neste artigo, ambas as condições são satisfeitas pela utilização dos estudos retóricos na análise dos pareceres.

\footnotetext{
${ }^{3}$ Sobre os primeiros, há o estudo de Bolívar (2008) baseado em 25 pareceres confidenciais enviados a três revistas da área de Humanidades.
} 
Com relação à caracterização do parecer de artigo científico publicado como gênero, é possível uma aproximação aos gêneros retóricos clássicos, a saber, o judiciário, o deliberativo e o epidítico, feita a ressalva de que

na realidade, embora esses gêneros sejam bem delimitados [por Aristóteles], dentro da mesma argumentação podem ocorrer traços dos três tipos de discurso, numa relação de dominância e não de exclusão (...) os diversos tipos de discurso convivem, na tentativa de ganhar a adesão do público e o seu assentimento, ou seja, de convencê-lo da validade da causa proposta e persuadi-lo à sua aceitação (MOSCA, 1997, p.32)

No caso em apreço, o gênero dominante é o deliberativo, tendo em vista, que o discurso tem, como finalidade, a tomada de decisão pelo editor (aceitar ou não o artigo para publicação) e o eixo de valores no qual se orienta é o da utilidade, ou seja se é útil à revista e a seus leitores a publicação do artigo em avaliação. Porém, considerando que o parecerista têm também um papel de juiz por lhe caber avaliar o mérito do artigo, há também traços do gênero judiciário, cuja finalidade está em acusar ou defender, haja vista que, ao parecerista, cabe a escolha entre argumentar a favor ou contra a publicação do artigo na revista. Como a qualidade da linguagem pode ser usada como argumento, não se pode descartar a possibilidade de a argumentação também se pautar no gênero epidítico, uma vez que pode haver censura ou elogio perante o uso da linguagem usada no artigo a qual envolve valores estéticos sobre o belo e o feio e pode, avalição que pode sobre o viés do preconceito linguístico.

O que Mosca denomina como o público a ser alcançado (1997), é concebido, na Nova Retórica, como o auditório presumido pelo orador definido como "o conjunto daqueles que o orador quer influenciar com sua argumentação" (PERELMANN; OLBRECHTES-TYTECA, 1996, p.22). No caso do parecer de artigo científico publicado, o parecerista, se propõe a convencer o editor da revista, o autor do texto e o público leitor.

A Retórica, enquanto estudo dos meios e estratégias existentes para a persuasão e o convencimento, distingue três tipos de argumentos, logos, pathos e ethos. A representação de si mesmo no discurso corresponde ao último tipo e concerne todas as escolhas feitas para que a audiência avalie o orador de uma dada maneira. O ethos do parecerista de artigo publicado, então, corresponde a como ele deseja ser avaliado por seus interlocutores. As análises apresentadas a seguir mostram as estratégias e os recursos empregados para a construção discursiva e retórica de três ethê: o ethos do parecerista objetivo, neutro e, por isso, "científico"; o ethos do parecerista respeitoso, polido e educado e o ethos do parecerista democrático e aberto.

Para melhor compreensão do conceito retórico de ethos aqui utilizado convém recuperar sua primordial definição aristotélica:

\begin{abstract}
(...) em retórica, o ethos é visto, primeiramente, como a representação que o orador imprime de si no ato retórico. É feito, resultado obtido pelo discurso e seu fim (...) é criação de uma impressão de si, elaborada pelo próprio orador e no próprio discurso para mostrar-se digno de confiança. Encontrar traços de honestidade e de virtude é o desejo natural de um auditório. Por isso, a credibilidade (...) é conseguida de modo eficiente quando o orador mostra em seu discurso que possui equidade, (...) senso de justiça, imparcialidade, isenção, neutralidade. (FERREIRA, 2019, p.14) (grifos nossos).
\end{abstract}

\title{
2 Constituição do corpus e metodologia empregada para sua análise
}

Tendo em vista a ausência de análise retóricas e baseada na Linguística Funcionalista sobre pareces publicados de artigos científicos em Língua Portuguesa, a metodologia empregada é de é cunho qualitativo-interpretativo, não chegando a se configurar como analítica tendo em vista que se trata de uma pesquisa exploratória pela qual houve criação de categorias ad-hoc que se acredita são adequadas tanto aos dados analisados quanto à fundamentação teórica adotada. Cumpre recortar que em pesquisas exploratórias como esta "são desenvolvidas com o objetivo de 
proporcionar visão geral, de tipo aproximativo, acerca de determinado fenômeno. Muitas vezes as pesquisas exploratórias constituem a primeira etapa de uma investigação mais ampla". (MOREIRA; CALEFFE, 2008, p. 71)

Para a constituição do corpus foram coletados, aleatoriamente, 05 pareceres publicados em 2019 e 5 publicados em 2020, os quais foram ordenados e numerados de 1 a 10 , conforme se pode ver na tabela 1 a seguir.

Tabela1. Corpus de pareceres

\begin{tabular}{|l|l|l|}
\hline No. & Título do artigo avaliado & Ano \\
\hline 1 & $\begin{array}{l}\text { Mediação Explícita e comportamento de busca da informação em bibliotecas } \\
\text { universitária }\end{array}$ & 2019 \\
\hline 2 & Comunicação científica visual: abordagens na ciência da informação & 2019 \\
\hline 3 & $\begin{array}{l}\text { Aspectos ontológicos e epistêmicos em terminologias clínicas: em busca de } \\
\text { interoperabilidade semântica no ambiente médico }\end{array}$ & 2019 \\
\hline 4 & $\begin{array}{l}\text { Recomendações para a integração de publicações ampliadas em repositórios } \\
\text { digitais confiáveis }\end{array}$ & 2019 \\
\hline 5 & Arte rupestre en Colombia: análisis cienciométrico & 2019 \\
\hline 6 & Linguística Documental Espanhola no Brasil: uma leitura crítica & 2020 \\
\hline 7 & $\begin{array}{l}\text { Proposta de modelo para análise das influências intelectuais dos bolsistas de } \\
\text { produtividade (pqs) do CNPq }\end{array}$ & 2020 \\
\hline 8 & Ciência-Ação em Ciência da Informação: um método qualitativo em análise & 2020 \\
\hline 9 & $\begin{array}{l}\text { Informação, Verdade e Pós-Verdade: uma crítica pragmaticista na ciência da } \\
\text { informação. }\end{array}$ & 2020 \\
\hline 10. & $\begin{array}{l}\text { Impacto da internacionalização na visibilidade da produção científica do } \\
\text { programa de pós-graduação em ciências biológicas: Bioquímica/UFRGS } \\
\text { (2007-2016) }\end{array}$ & 2020 \\
\hline
\end{tabular}

Para proceder à análise dos pareceres, foram selecionados determinados recursos linguísticos em consonância com a Gramática Sistêmico Funcional (HALLIDAY; MATTHIESSEN 2004, FUZER; CABRAL, 2014) e com a Nova Retórica (PERELMAN; OLBRECHTS-TYTECA, 1996), especificamente no que se refere aos elementos gramaticais e lexicais cujo uso estratégico foi descrito e analisado enquanto meios para escolha, adaptação e apresentação dos dados e da forma do discurso ${ }^{4}$.

Do primeiro ponto de vista, o parecer é um texto inserido num dado contexto de situação a qual se inclui num contexto de cultura. Em função do contexto de situação, se acionam as metafunções da linguagem: a ideacional, a interpessoal e a textual. Tendo em vista o propósito deste artigo, interessam os recursos linguísticos associados à metafunção interpessoal e que correspondem ao MODO, à modalidade e à usualidade. O MODO é responsável pela expressão da interação entre os participantes do evento comunicativo, no nível oracional, o MODO traz informação sobre o tempo do evento. A modalidade expressa um julgamento sobre a ação descrita na oração, se há probabilidade, usualidade, obrigação ou inclinação (FUZER ; CABRAL, 2014, p. 33) e informa também suas características epistêmica e deôntica. Analisando-se a primeira pode-se mensurar se ação é expressa como sendo certa, provável ou possível (probabilidade), se é ocasional, frequente ou constante (usalidade). Analisando-se a segunda, é possível elucidar se a ação é julgada como permitida, aceitável ou necessária e qual é a disposição para a ação, isto é, se, o agente está determinado, desejoso ou apenas inclinado a fazê-la (HALLIDAY, 1994). Tendo isto em vista, focam-se, na análise dos pareceres, os recursos linguísticos da interpessoalidade da língua portuguesa brasileira descritos por Fuzer e Cabral (2014,p.120), especialmente os verbos modais, os adjuntos modais, os adjuntos de comentário e as expressões modalizadoras.

\footnotetext{
${ }^{4}$ Os autores citados nesta seção são aqueles cuja metodologia e cujos pressupostos teóricos foram utilizados no decorrer na análise, ou seja, nesta seção do artigo, escolheu-se por fazer exclusivamente citações com a função de suporte ativo (CÁLLO-NASSI, 2014).
} 
Do segundo ponto de vista, o parecer é visto como um discurso e seu autor é um orador que se utiliza de argumentos de variados tipos para convencer seu auditório cujas características foram presumidas pelo orador. Para esmiuçar as potencialidades retóricas da escolha de um determinado recurso linguístico em detrimento de outro aprofundou-se a análise da escolha das qualificações (PERELMAN; OLBRECHTS-TYTECA, 1996, p.143-147), das formas verbais e das modalidades na expressão do pensamento (PERELMAN; OLBRECHTS-TYTECA, 1996, p.168188).

É necessário esclarecer que não se assume que os efeitos de sentido pretendidos sejam idênticos aos produzidos, nem que seja possível reconstituir cabalmente um ou outro. Adota-se, neste artigo, o mesmo procedimento adotado em estudo anterior (SEIDE, 2012, p. 123) para a análise retórica dos elementos coesivos em textos jornalísticos opinativos. Considera-se, como o faz Charaudeau, a existência de efeitos possíveis que abarcam os efeitos pretendidos. Como se sabe enquanto os efeitos pretendidos são elaborados na instância de comunicação, os produzidos são provenientes da instância da interpretação. Vale aqui retomar a definição de efeitos produzidos aqui considerada: "aqueles que o sujeito interpretante reconhece efetivamente, construindo-os e reconstruindo-os a seu modo [...] Os efeitos produzidos não coincidem, necessariamente, portanto, com os efeitos pretendidos (CHARAUDEAU, 2004, p.180).

\section{Estratégias retóricas de construção dos ethé presentes no corpus}

\subsection{O ethos do parecerista: o "objetivo", o "neutro" e o "científico"}

Os argumentos de ordem lógica e baseados em dados numéricos, costumam ser vistos como menos tendenciosos se comparados àqueles que se baseiam na interpretação de fatos. Vista como neutra e objetiva, a avaliação pela qual notas ou conceitos são atribuídos ao artigo que está em avaliação sem que haja a obrigatoriedade de justificativa tem sido cada vez mais empregada nas revistas científicas. Isto ocorre quando as revistas solicitam aos pareceristas que preencham um formulário e atribuam notas ou conceitos aos artigos a serem avaliados. A ausência de justificativa, o uso de verbos na terceira pessoa do singular e na voz passiva ou então de orações com sujeito que não corresponde ao agente da ação e a brevidade conseguida evitando-se o uso de advérbios, adjetivos e verbos modalizantes são características linguística desta estratégia, identificada nos pareceres 5, 6 e 9. O objetivo retórico de seu uso parece estar relacionado à preocupação por parecer científico, objetivo e preciso perante a audiência a quem se dirige: o autor, o editor e os leitores da revista.

O parecer 5 avaliou um artigo em língua espanhola e está escrito em língua portuguesa. No formulário de avaliação, os critérios de avaliação são descritos em forma de perguntas e há um espaço para o parecerista escrever a sua resposta, o último critério é chamado de "avaliação global", para este último, o formulário concede mais espaço para o parecerista detalhar sua avaliação. No caso desse artigo, o parecerista recuperou a estrutura frasal das perguntas, transformou-as em respostas afirmativas e acrescentou uma ou outra palavra. Apresenta-se a seguir a reunião das frases de cada quadro. Nesta reprodução, as palavras acrescentadas pelo parecerista estão em destaque.

O título está adequado ao conteúdo e reflete os assuntos tratados no trabalho. Os estudos apresentam limitações, como os interesses em outros pesquisadores e os problemas internos do país para pesquisas correlatas. O trabalho apresenta o recorte temporal, desde os primeiros trabalhos publicados até trabalhos recentes em 2018. A metodologia compreende os métodos e técnicas adotados no trabalho. O trabalho aplica corretamente os métodos propostos. As conclusões resumem assuntos tratados no trabalho. (PARECER 5)

Percebe-se a utilização de um dos recursos que promovem a impessoalidade: os sujeitos não são os agentes de ação. Por exemplo, na última frase do parecer, omite-se o agente, no caso, o autor do artigo. Então, ao invés de afirmar "Nas conclusões, o autor resume os assuntos tratados 
no trabalho", ele prefere a construção na qual as conclusões são o sujeito da frase e não há informação sobre o agente da ação.

Outra característica deste parecer é a brevidade. $\mathrm{Na}$ avaliação global do texto, a linguagem utilizada também é sintética, ou seja, o parecerista utiliza poucas palavras, mas percebe-se o uso de alguns recursos explicitam a consideração do parecerista pelo autor. Na segunda oração do parecer, há utilização do tempo futuro como substituto do modo imperativo no começo do texto (em destaque na reprodução a seguir) e a preocupação por justificar a alteração a ser feita, o que se percebe pelo uso da conjunção pois (também em destaque) e respectiva justificativa. Em consonância, com o uso da estratégia da impessoalidade, há nos períodos subsequentes e no último verbos na voz passiva sindética (os quais estão também em destaque):

\footnotetext{
"Recomendo para publicação com as alterações seguintes" (esta frase é parte do formulário)

Deverá formatar todo o trabalho com uma única fonte, pois não está padronizado quanto à fonte, na introdução, revisão de literatura e metodologia, utiliza-se "Arial” e, nos resultados e considerações finais, utiliza-se Times New Roman, deve padronizar a fonte. Outra recomendação, nas figuras e tabelas, utiliza-se a mesma fonte utilizada no corpo do trabalho. (PARECER 5)
}

Nos pareceres 6 e 9, o recurso à brevidade se intensifica a tal ponto que a avaliação é feita em apenas 22 palavras, contudo, tendo em vista à existência de um anexo, talvez haja outros comentários avaliativos, porém eles não estão acessíveis ao público. No formulário usado nesses pareceres, não se solicitam notas ao pareceristas e sim conceitos. Os pareceres são idênticos, as mesmas frases são usadas e os mesmos conceitos são atribuídos, fazendo crer que, do ponto de vista qualitativo, os artigos são equivalentes. Trata-se de um texto avaliativo bem resumido no qual há descrição do que precisa ser melhorado (avaliação negativa se bem amenizada pelo adjetivo "pequenos") na primeira frase, aspectos positivos que justificam a publicação na segunda. Observa-se que essas frases servem ao propósito de reconhecimento dos méritos do artigo para o autor e de argumento para a sua publicação para o editor. Trata-se, também, da expressão ou explicitação da conclusão a que o parecerista chegou após ler o artigo, conclusão que mostra que o artigo cumpriu com o seu propósito argumentativo. A preocupação por justificar a avaliação mostra ter havido consideração tanto pelo editor quanto pelo autor do artigo. Outra estratégia utilizada é o uso da $1^{a}$ pessoa do plural ao final do artigo. Pelo uso deste recurso, o parecerista se inclui na mesma comunidade formada pelo autor do texto e pelo editor da revista e ressalta a qualidade do artigo. Chama a atenção, também, a escolha de uma palavra-chave para o parecer positivo, a saber, a palavra inovação

Avaliação Geral: Trabalho precisa de pequenos ajustes conforme anexo. No mais, tem inovação e pouca explicação na CI. Precisamos discutir mais sobre o tema. (PARECERES 6 e 9).

Como se verá na seção seguinte, em pareceres mais longos, aumenta a utilização de recursos linguísticos que explicitam a consideração pelos interlocutores e também a descrição subjetiva do artigo em avaliação.

\subsection{O ethos do parecerista respeitoso, polido e educado}

O uso de recursos linguísticos que explicitam a consideração do parecerista perante o autor e o editor aumenta nos pareceres 1,4,7 e 8 do corpus, se bem, em cada um diferentes estratégias sejam utilizadas.

O parecer 4 é o que mais expressa avaliação negativa, o que se percebe pelo maior uso de palavras negativas, sufixos negativos e conjunções adversativas. Mesmo assim, percebe-se que o parecerista se preocupa em mostrar que tem consideração pelo autor do artigo científico que está 
avaliando. Certo apreço é expresso linguisticamente pela inserção de um elogio ao começo do parecer, pela estratégia da pessoalização (ao afirmar que ele não entendeu, abre-se a possibilidade mitigadora de a falha possa ser do leitor do texto) e do diálogo com o autor utiliza ao final do parecer quando o parecerista questiona o autor diretamente:

O tema é interessante, mas aparentemente é parte de uma dissertação ou tese sem a metodologia e com parte dos resultados. Não está indicado o critério para a seleção das iniciativas descritas na seção 3; inconsistências na numeração dos quadros e seções; as referências precisam de revisão e destaque. O quadro 1 apresenta vários problemas, primeiro não é elaboração própria, pois tem várias citações, é baseado em: mencionar os autores consultados. Não entendi a execução do item 5, a execução do item 6 exige a declaração explícita de alguma instituição, o mesmo para a execução dos itens 7, 8 e 9, bem como o detalhamento da equipe responsável, nos mesmos moldes usados em periódicos científicos. Por que o item 14 é inserção própria? (PARECER 4) (grifos nossos)

Já, no parecer 7, duas estratégias são adotadas para mostrar apreço e diminuir possíveis impactos negativos da avaliação.De um lado, há a ponderação entre elogios e críticas, o que se percebe pela escolha dos adjetivos. Dede outro, há usos de orações adversativas e orações adverbiais para justificar e descrever precisamente o que deve ser feito. A preocupação por ser didático indica que o parecerista procura ser colaborativo com o autor e tem por objetivo auxiliálo na tarefa de aperfeiçoar o artigo:

\footnotetext{
Num olhar amplo, o artigo apresenta uma redação excelente, com boa articulação teórica, domínio do tema e apresentação de diferentes possibilidades de análises envolvendo os métodos e ferramentas citados. Há boas relações construídas entre as possibilidades de estudos envolvendo a análise de citações.

Há pequenos ajustes que obrigatoriamente necessitam ser realizados que embora não interfiram no cerne do artigo, estão incorretos, que são:

- Os seguintes autores foram citados no artigo, mas não estão referenciados: Sirnelli (2003), Coniglio (1999), Bourdieu (1987) e Hjorland (2016).

- Necessário corrigir a palavra "assento" da página 13, o correto é "acento".

- A autoria do artigo afirma que há análise de conteúdo a partir de Bardin, entretanto, isto não fica explicitado no texto. Realizar uma análise das palavras-chave, resumos e títulos dos 602 artigos não se caracteriza como a análise de conteúdo de Bardin, que é composta por 3 etapas inseparáveis.

- A citação de Badiou (1972) na página 4 foi apresentada como citação direta e está incorreta (na forma em que se apresentou).

- A seção 3.2 possui um parágrafo introdutório que lista todas as etapas da proposta de modelo. Entretanto, logo em seguida, todas estas etapas novamente são mencionadas, deixando o texto repetitivo. $\mathrm{O}$ que eu recomendo é que este parágrafo introdutório seja excluído e substituído por uma figura que ilustre o modelo como um todo. Não há, nem no texto, uma ideia clara de que se trata de uma proposta de modelo de análise, ficou mais parecendo um checklist de tarefas, uma lista de procedimentos metodológicos, do que propriamente um modelo em si.(PARECER 7)
}

No parecer 8, além das estratégias utilizadas nos outros pareceres, há uma intensificação da estratégia da pessoalização e o uso de uma estratégia diferente: a simulação de diálogo conseguida pelo registro coloquial para se aproximar do autor na primeira frase e também pelos dizeres entre parênteses. Percebe-se, também, que são inseridos argumentos ao editor para que ele se convença do mérito do artigo (esses estão em itálico na reprodução a seguir), quer dizer, trata-se de um parecer com marcas explicitas de interação tanto com o autor quanto com o editor:

O estudo tem alguns errinhos bobos de português, porém passando por um pente fino pelas(os) autoras(es) pode ser sanado. Acredito que, pelo fato de no Brasil ainda não ter nenbum estudo desta natureza para a CI acredito ser se suma importância este tipo de trabalho. $\mathrm{O}$ estudo ainda está em desenvolvimento e é parte de uma tese, entretanto não acredito que tenha 
algum demérito em estar neste estágio. Os estudos de cunho social devem ser aceitos na área e os que implementam novas abordagens metodológicas também, afinal a CI tem enveredado para a quantificação de muitos de seus estudos e ficou carente deste processo mais reflexivo.

O único detalhe que poderia ser explorado com maior amplitude seria mostrar ações que já trazem efeito para a CI, segundo a abordagem da Competência em informação, como possíveis caminhos. Acredito que se complementar este argumento (que nada mais é do que 2 parágrafos) o trabalho fica à altura de ser publicado. Em relação aos requisitos de avaliação da revista, considero com um bom trabalho e com pequenas alterações (em especial de português e erros de digitação) deve ser publicado.

O parecer 1, por sua vez é o que mais utiliza meios de atenuar o dito, o que se consegue mediante a utilização de eufemismo. Sendo uma tentativa de atenuar aquilo que se julga possa causar reações negativas no interlocutor, o eufemismo é uma maneira de mostrar que há um maior apreço pelas audiências a quem se deseja convencer e persuadir, estando aí seu valor retórico.

O parecer número 1 começa com a descrição detalhada do artigo avaliado, na qual é possível discernir a descrição da contextualização da pesquisa e do objetivo, da metodologia e dos resultados, esta estruturação do resumo é explicitada, pelo parecerista, pelo uso de palavras em caixa alta e entre parêntese. Cumpre ressaltar que além da própria descrição do artigo do ponto de vista do parecerista ser, em si mesma, avaliativa e subjetiva, os usos de conjunção adversativa indicam que os pontos positivos colocados anteriormente serão ponderados pelos pontos fracos do artigo. Digno de nota é o gesto retórico de enumerar os argumentos positivos em primeiro lugar, sinal de apreço pelos interlocutores. O modo como a descrição dos ajustes foi feita demonstra que, do ponto de vista do parecerista, ao editor, cabe evidenciar que o artigo merece ser publicado e ao autor convém demonstrar a necessidade e a conveniência dos ajustes apontados:

O texto é fruto de uma dissertação de mestrado cujo objetivo foi discutir a mediação explícita e o comportamento de busca da informação em duas bibliotecas universitárias. (CONTEXTUALIZAÇÃO DA PESQUISA E OBJETIVO). A partir de entrevistas semiestruturadas, 11 bibliotecários expressaram seus conhecimentos sobre o conceito de mediação explícita e as ações que eles realizam com potencial de auxiliar no comportamento de busca da informação pelos usuários. As entrevistas foram analisadas por meio da Análise de Conteúdo (METODOLOGIA) indicando que os bibliotecários adotam práticas de mediação no seu dia a dia, mas têm dificuldades para definir o conceito de mediação e diferenciar as suas formas explícitas e implícitas. RESULTADOS)

. Avaliação

O artigo está adequado para uma publicação, mas ainda necessita de mudanças para corrigir erros gramaticais, esclarecer procedimentos metodológicos e inserir informações complementares.

Para melhorar a apresentação da pesquisa, sugerem-se algumas alterações e acréscimos:

1) O trabalho está bem redigido, mas necessita de uma revisão para corrigir o emprego da vírgula e da crase.

2) O resumo em inglês apresenta frases sem sujeito e iniciadas com verbo. Recomendase uma revisão para corrigir esses aspectos gramaticais.

3) Os procedimentos metodológicos, embora citados, aparecem apenas na segunda parte do artigo e de maneira sucinta. Assim sendo, recomenda-se também apontá-los nas seções introdutórias e com mais detalhamento, sobretudo no uso de categorias e subcategorias para a Análise de Conteúdo.

4) $\mathrm{Na}$ seção 4 (Comportamento informacional em biblioteca universitária), o autor(a) apenas lista os diferentes modelos de comportamento informacional sem esclarecer se adota ou defende algum modelo. Sugere-se indicar o posicionamento da pesquisa em relação a esses modelos, explicitando em qual ela se baseia, se for o caso.

5) Na seção 6 (Resultados), o autor(a) indica que os entrevistados relacionam a mediação explícita a um setor específico da biblioteca, mas não informa qual. Sugere-se inserir essa informação. 
6) As referências estão redigidas segundo a NBR 6023:2002. Caso a revista já adote a NBR 6023:2018, as referências devem ser revistas.

\section{(PARECER 1)}

A avaliação propriamente dita é expressa no parágrafo seguinte. À avaliação positiva configurada no uso do adjetivo "adequado", segue-se uma oração adversativa modalizada pelo advérbio "ainda" e pelo circunlóquio "precisa de mudança", que expressa uma instrução de modo eufemístico, tendo em vista que mesma instrução poderia ser feita de modo direto no imperativo: "corrija os erros gramaticais". Outro recurso de natureza eufemística é o uso de orações adverbiais finais para justificação de orações instrutivas que é ocorre nas orações sublinhadas no parecer 1 transcrito a seguir : "O artigo está adequado para uma publicação, mas ainda necessita de mudanças para corrigir erros gramaticais, esclarecer procedimentos metodológicos e inserir informações complementares." (PARECER 1). Assim o uso conjunto desses recursos resulta na atenuação do julgamento feito

Seguem-se, então, as instruções ao autor do artigo as quais são designadas, eufemisticamente como sendo sugestões as quais são, verdadeiramente, mudanças recomendadas. Tendo em vista que providenciá-las é condição para a publicação, não são realmente sugestões, mas sim obrigações, uma vez que a possibilidade de não obedecer aos comandos acarretaria na não publicação do artigo: "Para melhorar a apresentação da pesquisa, sugerem-se algumas alterações e acréscimos” (PARECER 1).

$\mathrm{Na}$ sequência são descritas 6 instruções. Nessas instruções, apesar de haver a utilização dos advérbios "apenas" e "não" e da preposição "sem" para fazer avaliação negativa, mantem-se a preocupação com o autor do texto. A primeira instrução inicia com um elogio e apresenta o uso estratégico de oração reduzida final para expressar instruções. Há eufemismo no uso dos verbos recomendar e sugerir e há também inclusão de justificativa na terceira instrução. Os recursos analisados estão em destaque na reprodução a seguir. Apenas na última instrução o parecerista não usa eufemismo, já que a obrigação da ação é expressa claramente pelo verbo dever:

1) O trabalho está bem redigido, mas necessita de uma revisão para corrigir o emprego da vírgula e da crase

2) O resumo em inglês apresenta frases sem sujeito e iniciadas com verbo. Recomenda-se uma revisão para corrigir esses aspectos gramaticais.

3) Os procedimentos metodológicos, embora citados, aparecem apenas na segunda parte do artigo e de maneira sucinta. Assim sendo, recomenda-se também apontá-los nas seções introdutórias e com mais detalhamento, sobretudo no uso de categorias e subcategorias para a Análise de Conteúdo.

4) $\mathrm{Na}$ seção 4 (Comportamento informacional em biblioteca universitária), o autor(a) apenas lista os diferentes modelos de comportamento informacional sem esclarecer se adota ou defende algum modelo. Sugere-se indicar o posicionamento da pesquisa em relação a esses modelos, explicitando em qual ela se baseia, se for o caso.

5) $\mathrm{Na}$ seção 6 (Resultados), o autor(a) indica que os entrevistados relacionam a mediação explícita a um setor específico da biblioteca, mas não informa qual. Sugere-se inserir essa informação.

6) As referências estão redigidas segundo a NBR 6023:2002. Caso a revista já adote a NBR 6023:2018, as referências devem ser revistas.

Nos pareceres analisados nesta seção, diferentes recursos linguísticos foram mobilizados pelos pareceristas visando a diminuição da percepção da assimetria de poder entre os interlocutores. Para além das aparências, relações interpessoais mais horizontais são estabelecidas quando a pessoa a quem fala é considerada como alguém capaz de discordar, como aquele a quem se dá o direito de não seguir as recomendações dadas, ou seja, como um indivíduo a quem é concedida certa liberdade de ação. Os pareceres analisados na última seção deste artigo apresentam indícios de relações mais abertas e democráticas que vão ao encontro dos ideais de Ciência Aberta. 


\subsection{O ethos do parecerista democrático e aberto}

Percebe-se que, no parecer 3, o parecerista usa estratégias modalizadoras já percebidas nos pareceres anteriores: uso da $1^{a}$. pessoa do singular e justificativa para a recomendação feita. Notase, também, um maior grau de subjetividade indicado pelo uso dos verbos parecer e achar:

Como observado no próprio texto, o autor faz citações e traz definições que acho importante sua localização na introdução, para melhor inteligibilidade dos conceitos empregados no artigo (...). Faço, no corpo do texto, todas as observações sobre o artigo. $\mathrm{O}$ texto encontra-se muito bem redigido, o autor possui pleno conhecimento sobre o assunto. Sugiro arrumar as citações de acordo com a ABNT NBR-10520. Também a primeira página do artigo não está de acordo com as normas da revista sobre a $1^{\mathrm{a}}$ e $2^{\mathrm{a}}$ laudas. Quanto ao título: (e partes do texto anotadas) não fica claro o que significa "epistemologia" no artigo. Me pareceu ser "epistêmica" que acho o termo mais adequado em conexão com a terminologia. Se assim for, teria que alterar o título também. No resumo fiz algumas observações em relação à explicitação do nome das linguagens e método/modelo de ancoragem. Ademais, as observações constam no texto (PARECER 3)

Esse parecer de destaca dos demais em virtude da oração condicional quase ao final do parecer a qual se refere à oração anterior. O julgamento do título é feito de modo subjetivo e relativizado mediante a escolha do verbo "parecer" que indica não uma certeza, mas uma possibilidade e do verbo achar indicando ser uma opinião pessoal do parecerista. A colocação da frase seguinte, no modo condicional e no tempo futuro, por sua vez, coloca a ação a ser feita pelo autor não no eixo da obrigatoriedade, mas sim no eixo da possibilidade, sendo-lhe permitido escolhe entre fazer ou não a ação recomentada. Neste contexto, o uso da condicional provoca uma abertura de interpretação na qual se admite a possibilidade de o parecerista não estar certo o que confere, ao autor, a incumbência de verificar e decidir se acata ou não o que é sugerido. Há aqui, por tanto, certa democratização da relação entre parecerista e autor do artigo.

Indícios de democratização também foram percebidos no parecer 2, o único do corpus que não apresenta uma avaliação inicial do artigo, mas sim uma avaliação posterior na qual o parecerista verifica em que medida os ajustes solicitados foram feitos e fazer a avaliação final. Se poderia pensar que se não fossem feitos, não se publicaria o artigo, porém, o que se percebe, nos trechos destacados do parecer reproduzido a seguir, é que a não obediência a algumas das solicitações não impediu a publicação do artigo:

Independentemente das sugestões fornecidas na revisão anterior do artigo os autores decidiram manter a delimitação da coleta de artigos na literatura às bases de dados dos principais meios de divulgação científica em Ciência da Informação (CI) no Brasil.(...) O estudo apresenta uma revisão integrativa a partir das bases de dados dos principais meios de divulgação científica em Ciência da Informação (CI) no Brasil. O estudo identificou uma lacuna na área de conhecimento de CI no que diz respeito a comunicação científica e visual. A revisão integrativa só resultou em um artigo na área de CI (além disso, como mencionado o artigo encontrado também foi elaborado em coautoria com um dos autores do estudo em questão) porém os autores decidiram delimitar a revisão da literatura às bases de dados dos principais meios de divulgação científica em Ciência da Informação (CI) no Brasil. (...) As alterações sugeridas na versão anterior do artigo foram realizadas e foi acrescentado um último parágrafo na Seção 4 (Considerações Finais) citando que outras áreas de conhecimento têm que serem levadas em conta para identificar as direções futuras na temática de documentos imagéticos como meio para comunicação e divulgação científica.(...) (PARECER 2) (grifos nossos)

Se infere, pela leitura do parecer, que, de todas as recomendações feitas aos autores, duas não foram providenciadas. O parecerista expressa esta não obediência usando o verbo decidir e os agentes da ação como sujeitos das orações o que atribui aos autores a responsabilidade por suas 
decisões. De qualquer forma, mesmo assim, o artigo foi publicado, isto é, aos autores foi dado o direito de acatar ou não as palavras do parecerista.

Considerando as informações contextuais fornecidas no início deste artigo, a atitude deste parecerista pode ser relacionada ao movimento político e científico da Ciência Aberta e à sua preocupação de criar o ethos de parecerista que adere ao esse movimento.

\section{CONSIDERAÇÕES FINAIS}

O advento do movimento da Ciência Aberta a partir de 2003, possibilitou a consolidação de revistas online e de acesso gratuito na área de Letras, no Brasil e no exterior. Sendo esta a primeira etapa do movimento, as próximas incluem a abertura do processo de avaliação dos artigos entre outras como o compartilhamento de dados primários e o depósito antecipado de artigos em repositórios de pré-print. A existência de revistas científicas brasileiras que possibilitam a publicação de pareceres de artigos é consequência deste movimento.

Tendo em vista este contexto, ao longo deste artigo, foram analisados 10 pareceres publicados na revista Encontros Bibli em 2019 e em 2020 com o objetivo de melhor compreender como os pareceristas configuram discursivamente o seu ethos retórico, isto é, a imagem forjada de si mesmos para o público almejado o qual, no caso de artigos publicado é formado pelo autor do artigo avaliado, pelo editor e pelos leitores da revista.

Com este propósito foram selecionados para análise, de um lado, os recursos linguísticos identificados pela Linguística Funcional como responsáveis pela função avaliativa do uso da linguagem e de outro os recursos linguísticos que são focados pela Nova Retórica e pela Retórica Clássica.

As qualidades do ethos clássico, segundo Aristóteles se centram na equidade, no senso de justiça, imparcialidade, isenção e neutralidade. Os resultados da análise do conjunto de pareceres publicado na revista Encontros Bibli mostram que o contexto da avaliação de artigos científico, os ideais da Ciência Aberta e a imagem de si buscada pelos pareceristas dos pareceres do corpus analisado resultaram numa reconfiguração das qualidades apontadas pelo filósofo.

A análise funcional e retórica empreendida identificou a existência de três ethé: a do parecerista objetivo de neutro, a do parecerista respeitoso, polido e educado e a do parecerista democrático e aberto os quais são construídos mediante a utilização de recursos linguísticos específicos que demonstram apreço pelo autor do artigo e preocupação por justificar ou ponderar as instruções dadas.

Apesar de a análise apresentada ao longo do artigo ter conseguido identificar, descrever e analisar diferentes imagens de si que os pareceristas projetam em seus pareceres há perguntas cuja respostas requerem pesquisas posteriores. De um lado, é preciso analisar pareceres publicado de outras áreas do conhecimento para saber se há configurações distintas do ethos em cada área e, de outro, é necessário fazer análises comparativas de pareceres publicados e pareceres não publicados a fim de saber se o fato de ser publicado influencia a construção da imagem de si do parecerista. Assim, numa pesquisa futura, seria interessante comparar os resultados apresentados com o obtidos por da Cruz (2012) que analisou pareceres não publicados de uma revista científica de Linguística. Apesar das limitações da pesquisa empreendida, cabe-lhe o mérito de ser a primeira a empreender uma análise retórica e funcionalista de artigos publicados no contexto da língua portuguesa.

Gostaria de deixar pública minha gratidão pelos pareceristas deste artigo que contribuíram sobremaneira para o aperfeiçoamento do meu texto e para minha própria formação como pesquisadora e escritora de artigos científicos. 


\section{REFERÊNCIAS}

ALBAGLI, Sarita; CLINIO, Anne; RAUCHTOCK, Sabryna. Ciência Aberta: correntes interpretativas e tipos de ação. Liinc em Revista, v.10.n.2, p.434-450,2014, Disp. Em http://www.ibict.br/liinc .Acesso em 24,nov.,2020.

$\begin{array}{llllll}\text { BEZIAK, Sonia et.al. Open } & \begin{array}{c}\text { Science } \\ \text { Acesso }\end{array} & \begin{array}{c}\text { Training } \\ \text { em }\end{array} \text { 24, } & \begin{array}{c}\text { Handbook. } \\ \text { novembro, }\end{array} & \begin{array}{r}\text { Disp.em } \\ \text { https://book.fosteropenscience.eu. }\end{array}\end{array}$
https://doi.org/10.5281/zenodo.1212496.

BOLÍVAR, Adriana. The negotiation of evaluation in written text. In: Patterns of text. In honour of Michael Hoey. SCHOTT, M.; THOMPSON, G.(eds). Amsterdam/Philadelphia: Jonh Benjamins Publishing Company, 2001, p.130-159.

BOLÍVAR, Adriana. El informe de arbitraje como género discursivo en la dinâmica de la investigación, ALED, v.8, n.1, p. 41-64 41, 2008.

CALO-NASSI, Lílian. Estudo propõe uma taxeonomia de razões para citar artigos em publicações científicas. Scielo em Perspectiva, 2014. Disp.em Estudo propõe uma taxonomia de razões para citar artigos em publicações científicas $\mid$ SciELO em Perspectiva . Acesso em 09/06/2021.

CHARAUDEAU, P. Dicionário de Análise do Discurso. São Paulo: Contexto, 2004.

DA CRUZ, Osilene Maria de Sá e Silva da. A avaliatividade em pareceres de revistas científicas de Linguística: uma perspectiva sistêmica-funcional. [tese de doutoramento] Programa de Pós-Graduação em Linguística Aplicada e Estudos da Linguagem da PUC-SP, 2012, 221 f.

FUZER, Cristiane; CABRAL, Sara Regina Scotta. Introdução à Gramática Sistêmico-Funcional em Lingua Portuguesa. Campinas, SP: Mercado de Letras, 2014.

FERREIRA, Luiz Antonio. "Introdução. Inteligência retórica e vocalidade: constituição e manutenção do ethos. In: Inteligência retórica: o ethos. São Paulo: Ed.Blucher ,2019, p.29-44.Disp.em https://openaccess.blucher.com.br/download-pdf/441 Acesso em 14/12/2020.

JOB, Ivone; MATTOS, Ana Maria; TRINDADE, Alexandre. Processo de revisão pelos pares: por que não rejeitados os manuscritos submetidos a um periódico científico? Movimento, 2009; vol.15, n.3, p.35-55.

MOSCA, Lineide do Salvador. Velhas e novas retóricas: convergências e desdobramentos. In: Retóricas de ontem e de hoje MOSCA, L.do S.(org.) São Paulo: Humanitas, 1997, p.17-54.

OLIVEIRA, Jane Raquel; PORTO, André Luiz M.; QUEIROZ, Salete Linhares. Peer review no ensino superior de Química: investigando aspectos estruturais e retóricos da linguagem científica valorizados pelos estudantes. Anais do XV Encontro Nacional de Ensino de Química (XV ENEQ) Brasília, DF, Brasil - 21 a 24 de julho de 2010, p.1- 12. SEIDE 2012.

MOREIRA, Erivelto; CALEFFE, Luiz Gonzaga. Metodologia da pesquisa para o professor pesquisador.2 ${ }^{a}$.ed. Rio de Janeiro: Lamparina, 2008.

PARECER para o artigo Mediação Explícita e Comportamento de busca da Informação em Bibliotecas Universitárias. Encontros Bibli, Florianópolis, v. 24, n.55, 2019. Disp .em v. 24 n. 55 
(2019) Encontros Bibli: revista eletrônica de biblioteconomia e ciência da informação (ufsc.br).Acesso em 24 nov.2020.

PARECER para o artigo. Comunicação científica visual: abordagens na ciência da informação Encontros Bibli, Florianópolis, v. 24, n.55, 2019. Disp .em v. 24 n. 55 (2019) | Encontros Bibli: revista eletrônica de biblioteconomia e ciência da informação (ufsc.br).Acesso em 24 nov.2020.

PARECER para o artigo. Aspectos ontológicos e epistêmicos em terminologias clínicas: em busca de interoperabilidade semântica no ambiente médico. Encontros Bibli, Florianópolis, v. 24, n.55, 2019. Disp .em v. 24 n. 55 (2019) | Encontros Bibli: revista eletrônica de biblioteconomia e ciência da informação (ufsc.br).Acesso em 24 nov.2020.

PARECER para o artigo. Arte rupestre en Colombia: análisis cienciométrico. Recomendações para a integração de publicações ampliadas em repositórios digitais confiáveis. Encontros Bibli, Florianópolis, v. 24, n.55, 2019. Disp .em v. 24 n. 55 (2019) | Encontros Bibli: revista eletrônica de biblioteconomia e ciência da informação (ufsc.br) Acesso em 24 nov.2020.

PARECER para o artigo Linguística Documental Espanhola no Brasil: uma leitura crítica. Encontros Bibli, Florianópolis, v. 25, 2020. Disp .em v. 25 (2020) | Encontros Bibli: revista eletrônica de biblioteconomia e ciência da informação (ufsc.br).Acesso em 24 nov.2020.

PARECER para o artigo. Proposta de modelo para análise das influências intelectuais dos bolsistas de produtividade (pqs) do CNPq Encontros Bibli, Florianópolis, v. 25, 2020. Disp .em v. 25 (2020) Encontros Bibli: revista eletrônica de biblioteconomia e ciência da informação (ufsc.br). Acesso em 24 nov.2020.

PARECER para o artigo. Ciência-Ação em Ciência da Informação: um método qualitativo em análise Encontros Bibli, Florianópolis, v. 25, 2020. Disp .em v. 25 (2020) | Encontros Bibli: revista eletrônica de biblioteconomia e ciência da informação (ufsc.br). Acesso em 24 nov.2020.

PARECER para o artigo. Informação, Verdade e Pós-Verdade: uma crítica pragmaticista na ciência da informação. Encontros Bibli, Florianópolis, v. 25, 2020. Disp .em v. 25 (2020) | Encontros Bibli: revista eletrônica de biblioteconomia e ciência da informação (ufsc.br). Acesso em 24 nov.2020.

PARECER para o artigo. Impacto da internacionalização na visibilidade da produção científica do programa de pós-graduação em ciências biológicas: Bioquímica/UFRGS (2007-2016) Encontros Bibli, Florianópolis, v. 25, 2020. Disp .em v. 25 (2020)| Encontros Bibli: revista eletrônica de biblioteconomia e ciência da informação (ufsc.br). Acesso em 24 nov.2020.

PERELMAN, Chaïm; OLBRECHTS-TYTECA, Lucie. 1994.[1992]. Tratado da Argumentação. São Paulo, Brasil: Martins Fontes, 1994 [1992].

PIOTR, Trzesniak; TATIANA Plata-Caviedes; OSCAR, Alejandro Córdoba-Salgado.2012. Revista colombiana de Psicología vol. 21 n. ${ }^{\circ} 1$ enero-junio 2012, p.57-78 Bogotá: Colombia.

VASCONCELLOS, Vinicius Gomes de. Editorial: controle por pares e a função do revisorpremissas e orientações para uma avaliação consistente. Rev. Bras. de Direito Processual Penal, Porto Alegre, vol. 3, n. 2, p. 437-458, mai.-ago. 2017.

SEIDE, Márcia Sipavicius.2012. "Funções retóricas da escolha dos elementos coesivos em textos jornalísticos informativos e opinativos". In Argumentação e Texto: revisitando conceitos, propondo 
análises, Sella, A.F.; Busse, S.; Corbari, A.T.(orgs), Cascavel, PR, Brasil/ Campinas, SP, Brasil: Pontes /Edunioeste.,2012, 119-144.

Submetido em 15/01/2021

Aceito em 13/07/2021 